\title{
Comparative assessment of angiotensin receptor blockers in different clinical settings
}

\author{
This article was published in the following Dove Press journal: \\ Vascular Health and Risk Management \\ II November 2009 \\ Number of times this article has been viewed
}

\author{
Paolo Verdecchia' \\ Fabio Angeli' \\ Salvatore Repaci' \\ Giovanni Mazzotta' \\ Giorgio Gentile 2 \\ Gianpaolo Reboldi² \\ 'Struttura Complessa di Cardiologia, \\ Unità di Ricerca Clinica 'Cardiologia \\ Preventiva', Ospedale S. Maria \\ della Misericordia, Perugia, Italy; \\ ${ }^{2}$ Dipartimento di Medicina Interna, \\ Università degli Studi di Perugia, Italy
}

Correspondence: Paolo Verdecchia Department of Cardiology, Clinical Research Unit "Preventive Cardiology", Hospital Santa Maria della

Misericordia, 06156 Perugia, Italy

$\mathrm{Tel}+390755782213$

Fax +39075 5782214

Email verdec@tin.it

\begin{abstract}
Cardiovascular and renal disease can be regarded as progressing along a sort of continuum which starts with cardiovascular risk factors (hypertension, diabetes, dyslipidemia, smoking, etc), evolves with progression of atherosclerotic lesions and organ damage, and then becomes clinically manifest with the major clinical syndromes (myocardial infarction, stroke, heart failure, end-stage renal disease). The blood pressure control remains a fundamental mechanism for prevention of cardiovascular disease. The renin-angiotensin system is believed to play an important role along different steps of the cardiovascular disease continuum. Convincing evidence accumulated over the last decade that therapeutic intervention with angiotensin receptor blockers (ARBs) is effective to slow down or block the progression of cardiovascular disease at different steps of the continuum, with measurable clinical benefits. However, despite the shared mechanism of action, each ARB is characterized by specific pharmacological properties that may influence its clinical efficacy. Indeed, important differences among available ARBs emerged from clinical studies. Therefore, generalization of results obtained with a specific ARB to all available ARBs may be misleading. The present review provides a comparative assessment of the different ARBs in their efficacy on major clinical endpoints along the different steps of the cardiovascular disease continuum.
\end{abstract}

Keywords: hypertension, renin-angiotensin system, valsartan, telmisartan, irbesartan, losartan, olmesartan, eprosartan

According to the chain of events described some years ago by Dzau and Braunwald, cardiovascular and renal disease, the most frequent causes of morbidity and mortality in industrial countries, can be regarded as progressing along a sort of continuum (Figure 1). ${ }^{1,2}$ The continuum starts with cardiovascular risk factors (hypertension, diabetes, dyslipidemia, smoking, etc) and evolves with progression of atherosclerotic lesions and organ damage. Hence, the continuum may become clinically manifest with the major clinical syndromes (myocardial infarction, stroke, heart failure, end-stage renal disease), which may ultimately lead to death. ${ }^{1,2}$

The outcome associated with late stages of the continuum is remarkably poor. For example, one out of two patients with New York Heart Association (NYHA) stage IV congestive heart failure dies within one year, and approximately $80 \%$ of all patients with congestive heart failure die within 10 years. ${ }^{3}$

It is important to note that therapeutic interventions at each step of the continuum can slow down or block its progression, with potentially measurable outcome benefits. In this setting, the blood pressure control remains a fundamental mechanism for prevention of cardiovascular disease. ${ }^{4}$ 


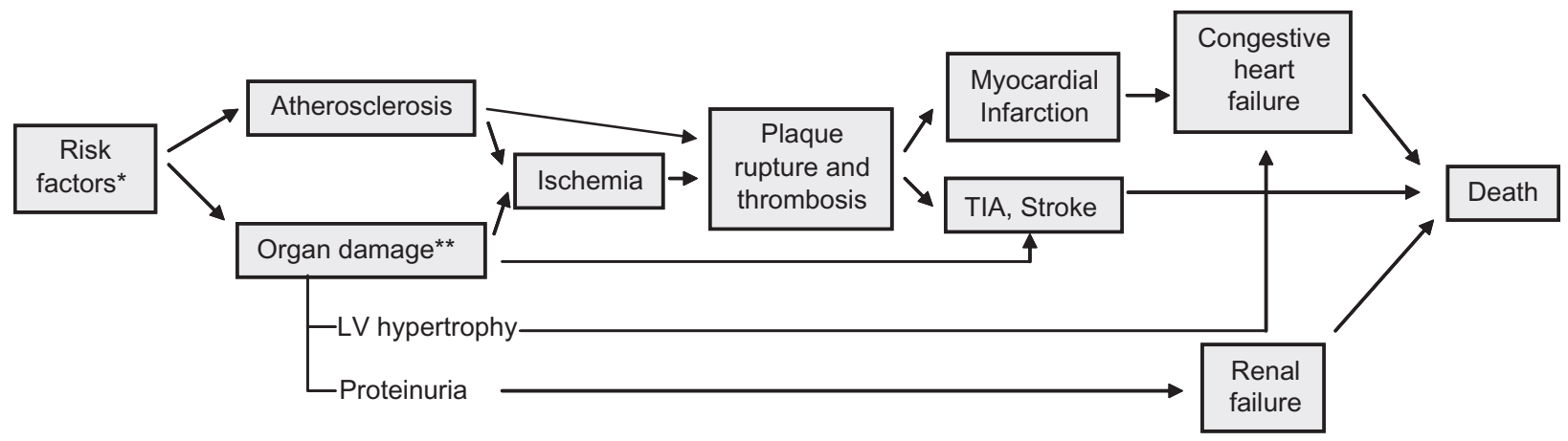

*Hypertension, diabetes, smoking, hypercholesterolemia, etc

${ }^{* *} \mathrm{LVH}$, proteinuria, vascular hypertrophy, plaques, asymptomatic

cerebrovascular disease, hypertensive retinopathy, atrial fibrillation

Figure I Cardiovascular disease continuum. Modified with permission from DzauVJ, Antman EM, Black HR, et al. The cardiovascular disease continuum validated:clinical evidence of improved patient outcomes: part II: Clinical trial evidence (acute coronary syndromes through renal disease) and future directions. Circulation. 2006; I 4(25):287|-289I.

\section{Role of the renin-angiotensin system}

Over the last two decades, a growing number of experimental and clinical studies provided evidence of an important role played by angiotensin II along the different steps of the cardiovascular disease continuum. ${ }^{5}$ It is well known that angiotensin II is produced through the aminoacid cleavage of angiotensin I operated by the angiotensin-converting enzyme (ACE) in some tissues including the lung, as well as in the myocardium, through the effects of specific proteases on angiotensin I.

Angiotensin II raises blood pressure (BP) through direct vasoconstriction mediated by AT1 receptor stimulation, and sodium and water retention mostly mediated by the stimulation of the synthesis of aldosterone. ${ }^{6}$ In addition, angiotensin II enhances oxidative stress by stimulating NADPH oxidase, with consequent generation of reactive oxygen species. ${ }^{7,8}$ Reactive oxygen species, by enhancing inactivation of nitric oxide produced by endothelial cells, accelerate the progression of atherosclerosis and induce plaque destabilization. ${ }^{7,8}$ Moreover, angiotensin II may trigger intracellular reactions leading to myocite and vascular hypertrophy, fibrosis and apoptosis. Finally, in patients with chronic congestive heart failure, activation of the renin-angiotensin system may contribute to the progressive remodeling and dilatation of cardiac chambers.

Stimulation of the AT2 receptors by angiotensin II is believed to promote biologic effects that are opposite to those of AT1 receptor stimulation. Indeed, AT2 receptor stimulation induces vasodilatation and inhibits fibrosis and inflammation. Although the effects of AT2 receptor stimulation are complex, the balance is believed to be positive. ${ }^{9}$

In patients taking ACE-inhibitors, the blunted production of angiotensin II and the consequent reduced stimulation of
AT1- and AT2 receptor may induce an 'escape phenomenon', which consists in the accumulation of angiotensin I and production of angiotensin II through alternative synthetic bio-pathways (cathepsine C, chimases). ${ }^{10}$ This phenomenon, well described in patients with congestive heart failure, may be prognostically important. For example, the risk of mortality in patients with heart failure under chronic treatment with ACE-inhibitors is directly related to the circulating levels of angiotensin II. ${ }^{11}$

\section{Impact of ATs receptor blockade}

The above scenario depicts a strong rationale for the specific and selective blockade of AT1 receptors through specific drugs. Of note, blockade of AT1 receptors is also accompanied by an over-stimulation of AT2 receptors by angiotensin II. The degree of AT2 stimulation is proportional to the selectivity of AT1 blockade. ${ }^{12}$

Over the last two decades, several AT1 receptor blockers (ARBs) have been extensively investigated at different steps of the cardiovascular disease continuum (Figure 2). Despite the common mechanism of action, each molecule is characterized by a distinct pharmacological profile and a different degree of AT1 selectivity, which is highest for valsartan. ${ }^{12}$ Obvious economic constrains precluded the executions of major outcome-based studies at each step for each of the available ARB drugs. On the other hand, however, the conclusions of studies conducted in a given clinical setting with specific ARBs are hardly applicable to different clinical settings or to different ARBs.

In view of the above considerations, the aim of the present review was to provide a comparative assessment of different ARBs at different steps of the cardiovascular disease continuum. Only the principal randomized intervention trials 


\begin{tabular}{|c|c|c|c|c|c|c|}
\hline & Hypertension & $\begin{array}{l}\text { High } \\
\text { vascular } \\
\text { risk }\end{array}$ & Stroke & $\begin{array}{l}\text { Diabetes } \\
\text { Nephropathy }\end{array}$ & $\begin{array}{l}\text { Congestive } \\
\text { heart } \\
\text { failure }\end{array}$ & $\begin{array}{l}\text { Myocardial } \\
\text { infarction }\end{array}$ \\
\hline Losartan & LIFE & & & RENAAL & $\begin{array}{l}\text { ELITE } \\
\text { ELITE II }\end{array}$ & OPTIMAAL \\
\hline Valsartan & $\begin{array}{l}\text { VALUE } \\
\text { JIKEI }\end{array}$ & & & $\begin{array}{l}\text { MARVAL } \\
\text { NAVIGATOR* }\end{array}$ & ValHeFT & VALIANT \\
\hline Candesartan & SCOPE & & $\begin{array}{l}\text { ACCESS } \\
\text { SCAST** }^{*}\end{array}$ & DIRECT & CHARM & \\
\hline Irbesartan & & & & $\begin{array}{l}\text { IRMA2, IDNT } \\
\text { IMPROVE }\end{array}$ & I-PRESERVE & \\
\hline Eprosartan & & & MOSES & & & \\
\hline Telmisartan & & $\begin{array}{l}\text { ONTARGET } \\
\text { TRANSCEND }\end{array}$ & PROFESS & $\begin{array}{l}\text { DETAIL } \\
\text { AMADEO } \\
\text { VIVALDI }\end{array}$ & & \\
\hline Olmesartan & & & & ROADMAP* & & \\
\hline
\end{tabular}

*Ongoing studies.

Figure 2 Major trials with angiotensin receptor blockers in specific cardiovascular conditions.

Abbreviations: CHARM, Candesartan in Heart failure: Assessment of Reduction in Mortality and morbidity; ELITE, Evaluation of Losartan in the Elderly; I-PRESERVE, Irbesartan in Heart Failure with Preserved Ejection Fraction Study; IRMA, Irbesartan in Patients with Type 2 Diabetes and Microalbuminuria; LIFE, Losartan Intervention for End Point Reduction; ONTARGET, Ongoing Telmisartan Alone and in Combination with Ramipril Global Endpoint Trial; OPTIMAAL, Optimal Trial in Myocardial Infarction with the Angiotensin II Antagonist Losartan; RENAAL, Reduction of Endpoints in NIDDM with the Angiotensin II Antagonist Losartan; SCOPE, Study on Cognition and Prognosis in the Elderly; VALIANT, Valsartan in Acute Myocardial Infarction; Val-HeFT, Valsartan Heart Failure Trial; VALUE, Valsartan Antihypertensive Long-term Use Evaluation.

were included in this review. Clinical trials have been retrieved from PubMed/MEDLINE using the terms 'renin-angiotensin system', 'angiotensin receptor blockers', 'hypertension', 'diabetic nephropathy', 'stroke', 'heart failure', and 'left ventricular hypertrophy'. We searched for studies published in any language up to March 31, 2009.

\section{Hypertension and high cardiovascular risk}

Arterial hypertension is probably the most important risk factor for cardiovascular diseases. At any age, there is a positive and graded relation between the usual BP and the risk of cardiovascular and stroke mortality. ${ }^{13}$ Intervention studies have conclusively demonstrated that a relation also exists between the degree of BP reduction and the outcome benefit. ${ }^{4,14}$

In patients with hypertension, the concomitance of additional risk factors, target organ damage or cardiac and renal disease substantially increases the total cardiovascular risk, requiring a more aggressive therapeutic approach with more stringent treatment goals, in order to prevent further progression of the cardiovascular continuum. ${ }^{15}$ In this respect, the role of renin-angiotensin system activation even in the early steps of the continuum has been confirmed by the positive results obtained with different ARBs in terms of reduction of cardiovascular morbidity and mortality in different populations.

The Study on Cognition and Prognosis in the Elderly (SCOPE) study ${ }^{16}$ was a double-blind, randomized study conducted in 4,964 patients aged 70-89 years, with systolic (160-179 mmHg) or diastolic (90-99 mmHg) hypertension and a Mini Mental State Examination test score $>24$. Patients were randomized to candesartan titrated to $16 \mathrm{mg}$ once daily or placebo on top of other antihypertensive drugs as needed by the single patients. Consequently, active drugs were used by $84 \%$ of patients in the placebo group. The mean duration of follow-up was 3.7 years. The primary outcome, a composite of cardiovascular death, nonfatal stroke and nonfatal myocardial infarction, occurred in $26.7 \%$ of patients in the candesartan group and $30.0 \%$ of patients in the placebo group (risk reduction 10.9\%; $P=0.19$ ). Candesartan-based treatment reduced nonfatal stroke by $27.8 \%$ (95\% confidence interval $[\mathrm{CI}]: 1.3$ to $47.2 ; P=0.04)$, and all stroke by $23.6 \%$ (95\% CI: -0.7 to $42.1 ; P=0.056)$. There were no differences 
between the candesartan group and the placebo group with regard to dementia, cognitive decline or mean change in Mini Mental State Examination test.

The Losartan Intervention for End Point Reduction (LIFE) study ${ }^{17}$ was designed to compare a treatment based on losartan with a treatment based on atenolol in patients with hypertension and left ventricular (LV) hypertrophy diagnosed by electrocardiography. Overall, 9193 patients were randomized to losartan titrated to $100 \mathrm{mg}$ daily or atenolol titrated to $100 \mathrm{mg}$ daily and followed for a mean of 4.8 years. The primary cardiovascular event, a composite of death, myocardial infarction, or stroke occurred in $11 \%$ of patients allocated to losartan and $13 \%$ of patients allocated to atenolol $(P=0.021)$ despite a similar reduction of BP in the two groups. Stroke was the only component of the primary endpoint which was significantly reduced by losartan compared to atenolol ( $5 \%$ vs $7 \% ; P=0.001)$.

In the Valsartan Antihypertensive Long-term Use Evaluation (VALUE) study, ${ }^{18}$ 15,245 hypertensive patients aged 50 years or older were randomly allocated in a doubleblind fashion to valsartan (80-160 mg daily) or amlodipine (5-10 mg daily). The mean duration of follow-up was 4.2 years. The primary endpoint was a composite of cardiac mortality and morbidity. Although BP was reduced by both treatments, the effects of amlodipine were more pronounced, especially during the first months of the study. Despite the better BP control achieved in the amlodipine group, the primary composite endpoint occurred almost equally in the two groups $(10.6 \%$ vs $10.4 \% ; P=0.49)$, and the rate of fatal and nonfatal stroke (a secondary outcome measure of the study) was similar between treatments. New-onset diabetes, a prespecified endpoint, occurred at a rate of 32.1 per 1,000 patient-years in the valsartan group, and 41.1 per 1,000 patient-years in the amlodipine group (23\% risk reduction in the valsartan group, $P<0.0001$ ).

In the JIKEI study, ${ }^{19} 3,081$ Japanese patients aged between 20 and 79 years (mean, 65 years) who were receiving a conventional treatment for high BP, coronary heart disease or heart failure were randomly assigned to valsartan (40-160 mg per day) or to a treatment without ARBs according to a prospective, randomized, open-label blinded-endpoint (PROBE) design. The primary endpoint was a composite of cardiovascular morbidity and mortality (admission to hospital for stroke, transient ischemic attack, myocardial infarction, congestive heart failure, angina pectoris, dissecting aneurysm of the aorta). During a median follow-up of 3.1 years, the primary endpoint occurred in $6.0 \%$ of patients receiving valsartan and $9.7 \%$ of patients not receiving ARBs (hazard ratio
$0.61 ; P=0.0002)$. This difference was largely accounted for by $40 \%$ lower incidence of stroke and TIA in the valsartan group compared to the control group $(1.9 \%$ versus $3.1 \% ; P=$ $0.028)$. In addition, also angina pectoris requiring hospitalization $(1.2 \%$ versus $3.4 \% ; P=0.0001)$ and heart failure $(1.2 \%$ versus $2.3 \% ; P=0.029$ ) were less frequent in the valsartan group than in the control group. Mortality did not differ between the two groups.

In the Ongoing Telmisartan Alone and in Combination with Ramipril Global Endpoint Trial (ONTARGET) study, ${ }^{20}$ 25,620 patients with a variety of conditions sharing an increased vascular risk (history of coronary artery disease, cerebrovascular disease, peripheral occlusive disease or diabetes with organ damage) were randomized to ramipril $10 \mathrm{mg}$ daily, telmisartan $80 \mathrm{mg}$ daily or the combination of both. Duration of follow-up was five years. The primary endpoint, a composite of nonfatal myocardial infarction, nonfatal stroke, cardiovascular death or hospitalization for heart failure occurred in $16.5 \%$ of patients allocated to ramipril, $16.7 \%$ of patients allocated to telmisartan and $16.3 \%$ of patients in the combination group. The prespecified hypothesis of noninferiority of telmisartan versus ramipril was demonstrated $(P=0.001)$ and the results were consistent across the single components of the primary outcome. However, the combination of telmisartan and ramipril did not differ from ramipril alone $(P=0.38)$ and was associated with a higher incidence of adverse events including hypotension, syncope and renal dysfunction. ${ }^{20}$ These findings suggest that the degree of renin-angiotensin system activation or angiotensin II escape may not have been so high in these patients to benefit from a dual blockade of the renin-angiotensin system.

Differences among the available ARBs have been documented in head-to-head comparative studies. In general, the new-generation ARBs including irbesartan, ${ }^{21}$ telmisartan, ${ }^{22}$ candesartan, ${ }^{23}$ and valsartan ${ }^{24}$ proved more effective than losartan in lowering BP in hypertensive patients.

\section{Implications in patients with hypertension and high cardiovascular risk}

Although all ARBs are effective in lowering BP, only a few event-based studies have demonstrated the value of this class of drugs in reducing cardiovascular events in patients with hypertension and high cardiovascular risk. Taken together, these studies suggest that:

(a) Losartan demonstrated better efficacy than the betablocker atenolol in reducing cardiovascular morbidity and mortality, accounted for by a reduction of stroke. 
(b) Valsartan demonstrated similar efficacy on cardiovascular morbidity and mortality versus amlodipine, despite better BP control obtained with the calcium channel blocker. When used on top of optimized treatment, valsartan induced a reduction of cardiovascular morbidity and mortality, accounted for by a positive effect on the occurrence of stroke, angina, and heart failure.

(c) Telmisartan was the only ARB which demonstrated therapeutic equivalence versus the ACE-inhibitor ramipril.

\section{Myocardial infarction}

Patients with acute myocardial infarction frequently present with signs and symptoms of heart failure or left ventricular dysfunction. In these patients, ACE-inhibitors are effective in reducing mortality and morbidity, especially in the subsets at higher risk. ${ }^{25}$

Two major studies tested the hypothesis that an ARB was noninferior or superior to an ACE-inhibitor in these patients.

In the Optimal Trial in Myocardial Infarction with the Angiotensin II Antagonist Losartan (OPTIMAAL), ${ }^{26}$ 5,477 patients aged 50 years or more (mean age 67 years) with acute myocardial infarction and heart failure during the acute phase or a new Q-wave anterior infarction or reinfarction, were randomized to losartan titrated to $50 \mathrm{mg}$ once daily or captopril titrated $50 \mathrm{mg}$ three times daily. The primary endpoint was all-cause mortality. The trial was designed as a noninferiority trial of losartan versus captopril, with a prespecified right-sided noninferiority margin (95\% confidence margin) of 1.10 . Over a mean follow-up of 2.7 years, there were 499 deaths $(18 \%)$ in the losartan group and 447 deaths (16\%) in the captopril group (relative risk $1.13 ; 95 \%$ CI: $0.99-1.28 ; P=0.07)$. Since the achieved upper $95 \%$ confidence margin (1.28) was superior to the prespecified value of 1.10, the OPTIMAAL trial did not satisfy the prespecified criteria for noninferiority of losartan versus captopril. As expected, losartan was better tolerated than captopril, with fewer patients discontinuing study medication (17\% vs 23\%; $P<0.0001)$.

The Valsartan in Acute Myocardial Infarction (VALIANT) trial $^{27}$ was a double-blind, randomized comparison between captopril titrated to $50 \mathrm{mg}$ three times daily, valsartan titrated to $160 \mathrm{mg}$ twice daily and their combination in 14,703 patients with myocardial infarction complicated by LV systolic dysfunction, heart failure, or both. The primary endpoint was all-cause mortality. Duration of follow-up was 24.7 months. The trial was designed as a noninferiority trial of valsartan versus captopril, with a prespecified upper $97.5 \%$ confidence limit of 1.13. During follow-up, 958 patients died in the captopril group, 979 patients died in the valsartan group, and 941 patients died in the valsartan plus captopril group. The hazard ratio in the valsartan group compared to the captopril group was 1.00 and its $97.5 \% \mathrm{CI}$ ranged between 0.90 and $1.11(P=0.98)$. Therefore, since the achieved upper $97.5 \%$ confidence margin (1.11) was within the prespecified margin of 1.13 , the VALIANT study satisfied the prespecified criteria for noninferiority of valsartan versus captopril $(P=0.004)$. The valsartan plus captopril combination was not superior to captopril alone $(P=0.73)$ and the adverse events, particularly hypotension and renal dysfunction, were more frequent in the combination group. The statistical techniques of imputing placebo (Figure 3) showed that the size of the estimated benefit of valsartan in this study was comparable to that observed in three major placebo-controlled studies conducted with ACE-inhibitors in this kind of patients.

Results of VALIANT are consistent with those of ONTARGET in showing the lack of additional outcome benefits by the dual blockade of the renin-angiotensin system in patients at high vascular risk (ONTARGET) or after myocardial infarction complicated by left ventricular dysfunction or heart failure (VALIANT). As discussed above, these data suggest that the degree of renin-angiotensin system activation may be not so high to require a dual blockade in these patients.

\section{Implications in patients with myocardial infarction}

The above data suggest that, in patients with myocardial infarction and evidence of heart failure of left ventricular dysfunction:

(a) Valsartan, titrated up to $160 \mathrm{mg}$ twice daily, provides the same benefits, in terms of survival and cardiovascular events, as captopril titrated up to $50 \mathrm{mg}$ three times daily

(b) These results can not be extended to losartan $50 \mathrm{mg}$ daily, which, contrary to valsartan, failed to demonstrate noninferiority versus captopril titrated up to $50 \mathrm{mg}$ three times daily in a comparable cohort of patients.

\section{Congestive heart failure}

Activation of the renin-angiotensin system is a typical feature in chronic heart failure and its inhibition remains an important therapeutic target in these patients. However, it has been clearly demonstrated that morbidity and mortality remain very high in patients with chronic heart failure despite current standard medical therapy with diuretics, beta-blockers, 


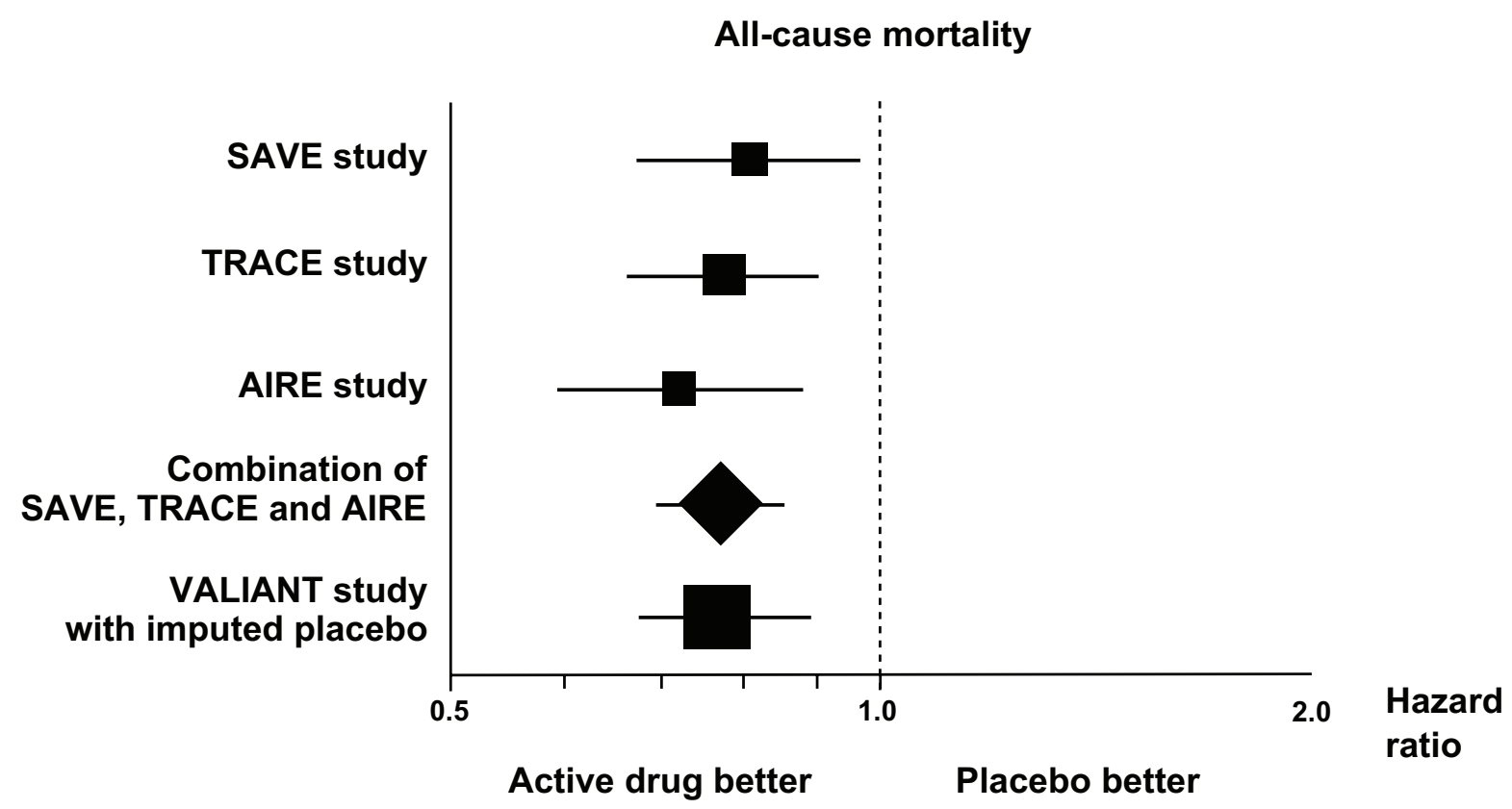

Figure 3 Effects on all-cause mortality in trials with ACE-inhibitors and in the VALIANT trial (with imputed placebo) in patients with myocardial infarction and evidence of heart failure or left ventricular dysfunction (hazard ratios and $95 \%$ confidence intervals). Copyright $($ I 999 . Modified with permission from Mallion J, Siche J, Lacourciere Y. ABPM comparison of the antihypertensive profiles of the selective angiotensin II receptor antagonists telmisartan and losartan in patients with mild-to-moderate hypertension. J Hum Hypertens. 1999; I3(10):657-664.

Abbreviations: SAVE, Survival and Ventricular Enlargement trial; TRACE, Trandolapril Cardiac Evaluation;AIRE, Acute Infarction Ramipril Efficacy trial.

ACE-inhibitors, and aldosterone antagonists. The need to improve outcome in these patients, as well as the evidence of an escape phenomenon to ACE-inhibitors, prompted several major trials specifically designed to investigate two main aspects: (a) head-to-head comparison between ACE-inhibitors and ARBs; (b) assessment of the clinical value of complete suppression of the renin angiotensin system, as provided by the combination of ACE-inhibitors with ARBs, in comparison with either component alone.

\section{Congestive heart failure with reduced ejection fraction}

In the Evaluation of Losartan in the Elderly (ELITE) study, ${ }^{28}$ 722 patients with heart failure NYHA class II-IV and ejection fraction of $40 \%$ or less were randomized to losartan titrated to $50 \mathrm{mg}$ once daily or captopril titrated to $50 \mathrm{mg}$ three times daily. Duration of follow-up was 48 weeks. The primary endpoint was the persisting increase in serum creatinine, the secondary endpoint was a composite of death and hospital admission for heart failure. While the primary endpoint did not differ between the groups, the secondary endpoint occurred in $9.4 \%$ of patients in the losartan group and $13.2 \%$ of patients in the captopril group (risk reduction $32 \% ; P=0.075$ ). Total mortality was significantly lower in the losartan group $(4.8 \%)$ than in the captopril group $(8.7 \%)(P=0.035)$.
The encouraging results of ELITE study prompted the execution of the Evaluation of Losartan in the Elderly (ELITE) II Study. ${ }^{29}$ In this study, 3,152 patients with heart failure NYHA class II-IV and LV ejection fraction of $40 \%$ or less were randomized to losartan titrated $50 \mathrm{mg}$ once daily or captopril titrated $50 \mathrm{mg}$ three times daily. The study, planned as a superiority trial, was designed to test the hypothesis of a $30 \%$ reduction in mortality in the losartan group with respect to captopril. There were no significant differences in all-cause mortality between losartan (11.7\%) and captopril (10.4\%). Also the other prespecified endpoints did not differ between the groups. Losartan was better tolerated than captopril, as suggested by the lower rate of discontinuation due to adverse effects $(9.7 \%$ vs $14.7 \% ; P<0.001)$. Thus, ELITE II suggested that losartan is not superior to captopril in patients with heart failure, although it might offer an advantage in patients unable to tolerate ACE-inhibitors because of cough or angioedema.

The Valsartan Heart Failure Trial (Val-HeFT) ${ }^{30}$ was a randomized, placebo-controlled, double-blind study between valsartan titrated to $160 \mathrm{mg}$ twice daily and placebo in 5,010 patients with heart failure and LV ejection fraction of $40 \%$ or less. The mean duration of follow-up was 23 months. The incidence of primary composite endpoint of mortality and morbidity (defined as resuscitated cardiac arrest or rehospitalization for heart failure) was lower by $13.2 \%$ in the 
valsartan group compared to the placebo group $(P=0.009)$. All-cause mortality did not differ between the groups (19.7\% vs $19.4 \%$ ). The most frequently used ACE-inhibitors were enalapril, lisinopril, captopril, ramipril and quinapril at a mean daily dose of $17 \mathrm{mg}, 19 \mathrm{mg}, 80 \mathrm{mg}, 6 \mathrm{mg}$ and $23 \mathrm{mg}$, respectively. The Val-Heft study suggested that a full blockade of the renin-angiotensin system by adding valsartan to ACE-inhibitors in patients with heart failure and reduced ejection fraction reduces the combined endpoint of morbidity and mortality. This may be due to the very high degree of renin-angiotensin system activation in these patients, requiring a dual blockade to be fully reversed. An unexpected finding from a post hoc analysis of the Val-Heft study was a significant adverse effect of valsartan on outcome in the subset of patients who were being treated with both an ACE-inhibitor and a beta-blocker at baseline. These findings were not confirmed in the Candesartan in Heart failure: Assessment of Reduction in Mortality and morbidity (CHARM)-ADDED trial, where the effect of candesartan were maintained in the subgroup of patients treated with beta-blockers. $^{31}$

The CHARM-ALTERNATIVE study ${ }^{32}$ compared the effects of candesartan, titrated to $32 \mathrm{mg}$ daily, with placebo in 2,028 patients with heart failure and LV ejection fraction of $40 \%$ or less who were both treated at best of their condition and intolerant to ACE-inhibitors. As compared to placebo, candesartan significantly reduced the primary composite endpoint of cardiovascular death or hospitalization for heart failure (33\% vs $40 \%$, hazard ratio 0.77 ; $P=0.0004$ ) after a median follow-up of 33.7 months. All-cause mortality did not differ between the groups.

In the CHARM-ADDED trial, ${ }^{31} 2,548$ patients with heart failure and LV ejection fraction of $40 \%$ or less who were treated with a background therapy including ACEinhibitors and other drugs (but excluding ARBs) were randomized to candesartan titrated to $32 \mathrm{mg}$ daily or placebo. The median follow-up was 41 months. Candesartan reduced the primary composite outcome (the same as in CHARMALTERNATIVE) by $15 \%(P=0.011)$. However, the rate of all-cause mortality did not differ $(P=0.086)$ between candesartan $(30 \%)$ and placebo $(32 \%)$. In this study, the ACE-inhibitors more frequently used were enalapril, lisinopril, captopril and ramipril at a mean daily dose of $17 \mathrm{mg}$, $17 \mathrm{mg}, 82 \mathrm{mg}$ and $7 \mathrm{mg}$, respectively. Overall, the study suggested that a complete blockade of the renin-angiotensin system achieved by adding candesartan to ACE-inhibitors is useful in patients with heart failure and reduced ejection fraction.

\section{Congestive heart failure with 'normal' ejection fraction}

It is well known that ejection fraction is $45 \%$ or higher in about half of patients with congestive heart failure. The prognostic impact of congestive heart failure with normal ejection fraction is controversial, as well as the most appropriate treatment in these patients.

In the CHARM-PRESERVED study, ${ }^{33}$ 3,023 patients with chronic heart failure and LV ejection fraction greater than $40 \%$ were randomized to candesartan titrated to $32 \mathrm{mg}$ daily or placebo on top of their background therapy. The primary outcome was cardiovascular death or admission to hospital for congestive heart failure. Duration of follow-up was 37 months. The incidence of primary outcome was $22 \%$ with candesartan and $24 \%$ with placebo $(P=0.118)$. While cardiovascular death did not differ between the groups, fewer patients in the candesartan group had a new hospitalization for re-exacerbation of heart failure once ( 230 vs 279; $P=0.017$ ). About $19 \%$ of patients received also an ACE-inhibitor, 55\% a beta-blocker and $11 \%$ received spironolactone.

The Irbesartan in Heart Failure with Preserved Ejection Fraction Study (I-PRESERVE) ${ }^{34}$ was a comparative study between irbesartan $300 \mathrm{mg}$ daily and placebo in 4,128 patients aged 60 years or more and heart failure with LV ejection fraction greater than $40 \%$. Duration of follow-up was 49.5 months. The primary composite endpoint (all-cause death or hospitalization for heart failure, myocardial infarction, unstable angina, arrhythmia, or stroke) occurred in $742(36.0 \%)$ patients in the irbesartan group and $763(37.0 \%)$ in the placebo group $(P=0.35)$. All-cause mortality and the rate of hospitalization did not differ between the groups $(P=0.98$ and $P=0.44$, respectively). There were no significant differences in the other prespecified endpoints. Interestingly, about $25 \%$ of patients received an ACE-inhibitor, 58\% a beta-blocker and $15 \%$ received spironolactone.

\section{Implications in patients with heart failure}

Taken together, these data suggest that, in patients with chronic congestive heart failure, reduced ejection fraction and concomitant treatment with ACE-inhibitors:

(a) Losartan was not superior to captopril in reducing allcause mortality or cardiovascular events. The relatively low dose of losartan $(50 \mathrm{mg})$ may contribute to explain these results.

(b) The combined blockade of the renin-angiotensin system achieved by valsartan titrated to $320 \mathrm{mg}$ daily, or candesartan titrated to $32 \mathrm{mg}$ daily, in addition to 
ACE-inhibitors, reduced the composite endpoint of all-cause mortality and hospitalization for heart failure. These data suggest that an incomplete blockade of the renin-angiotensin system, possibly associated with the 'escape' phenomenon under ACE-inhibition, may be an important basic mechanism explaining the high risk of morbidity and mortality in these patients.

(c) Since none of the other available ARBs has been investigated in outcome-based studies in these patients with poor short- and long-term outcome, extrapolation of results obtained with valsartan and candesartan to other ARBs should not be allowed.

Conversely, as resulting from studies with candesartan and irbesartan, there is no evidence that AT1 blockade reduces the primary outcome of morbidity and mortality in patients with chronic heart failure and preserved ejection fraction, although a modest benefit with candesartan may be observed in terms of fewer hospitalization for heart failure.

\section{Diabetic nephropathy}

Approximately $40 \%$ of patients with type 2 diabetes develop nephropathy, which is the main determinant of end-stage renal disease. Prevention, early identification and appropriate treatment of nephropathy in these patients are therefore of vital importance. Reduction of proteinuria is associated with renal and cardiovascular protection. There is large evidence from animal and human studies that inhibition of the renin-angiotensin system reduces proteinuria. ${ }^{35,36}$

In this setting, the evidence that ACE-inhibitors reduce proteinuria and slow the progression of renal damage in patients with type 1 diabetes can not be extrapolated to patients with type 2 diabetes because of the substantial differences between these two groups of patients in terms of potential mechanisms of glomerular disease and demographic and metabolic features. Over the last decade, several studies conducted with ARBs in patients with type 2 diabetes provided important data for a better management of these patients. In particular, three major trials were conducted in patients with type 2 diabetes and early (one study) or more advanced (two studies) nephropathy.

In the Irbesartan in Patients with Type 2 Diabetes and Microalbuminuria (IRMA) study, ${ }^{37} 590$ hypertensive patients with type 2 diabetes and early nephropathy (defined by microalbuminuria) were randomized to placebo, irbesartan $150 \mathrm{mg}$ or irbesartan $300 \mathrm{mg}$ on top of background therapy and followed for two years. The primary outcome was the time to onset of diabetic nephropathy, defined by persistent albuminuria ( $>200 \mu \mathrm{g}$ per minute). The primary endpoint was achieved by $14.9 \%$ of patients with placebo, $9.7 \%$ of patients with irbesartan $150 \mathrm{mg}(P=0.08)$ and $5.2 \%$ of patients with irbesartan $300 \mathrm{mg}(P=0.001)$. These effects were independent of BP changes.

In the Reduction of Endpoints in NIDDM with the Angiotensin II Antagonist Losartan (RENAAL) study, ${ }^{38}$ 1,513 patients with type 2 diabetes and nephropathy were randomized to losartan titrated to $100 \mathrm{mg}$ per day, or placebo, on top of conventional treatment. Follow-up lasted a mean of 3.4 years. The primary outcome, a composite of doubling of the baseline serum creatinine, end-stage renal disease, or death occurred in $43.5 \%$ of patients in the losartan group and $47.1 \%$ of patients in the placebo group ( $16 \%$ risk reduction, $P=0.02)$.

The Irbesartan Diabetic Nephropathy Trial (IDNT) ${ }^{39}$ was a randomized, double-blind comparison between irbesartan $300 \mathrm{mg}$, amlodipine $10 \mathrm{mg}$ and placebo in 1,715 hypertensive patients with type 2 diabetes and established nephropathy with macroproteinuria. Duration of follow-up was 2.6 years. The incidence of a primary composite endpoint consisting of doubling of serum creatinine, development of end-stage renal disease, or death from any cause, was reduced by $20 \%$ with irbesartan compared to placebo $(P=0.02)$, and by $23 \%$ with irbesartan compared to amlodipine $(P=0.006)$. Similarly to the IRMA study, these differences were not explained by differences in achieved BP between the treatments. There were no significant differences between the groups in the rate of death from any cause or cardiovascular events.

\section{Implications in patients with diabetes and nephropathy}

Overall, these data suggest that: in patients with type 2 diabetes and early nephropathy (microalbuminuria), irbesartan $300 \mathrm{mg}$ is more effective than placebo in preventing the progression to macroproteinuria. In patients with type 2 diabetes and more advanced nephropathy (macroproteinuria), losartan is more effective than placebo, and irbesartan more effective than placebo and amlodipine, in preventing the composite outcome of end-stage renal disease, doubling of serum creatinine or death.

\section{Conclusions}

The overall message of the trials examined in this review is that intervention with ARBs at different steps of the cardiovascular disease continuum is effective to slow down or block the disease progression, with consequent measurable benefits. However, generalization of results to all available 
ARBs for any step of the continuum may be misleading because differences among available ARBs emerged from these studies.

In deciding the choice of the ARB in the individual patient along specific steps of the cardiovascular disease continuum, the driving concept should be that, despite the shared mechanism of action, each molecule is characterized by specific pharmacological properties that are likely to influence its clinical efficacy. Therefore, according to the principles of evidence-based-medicine, the tempting attitude of applying conclusions of studies conducted in specific clinical settings with a specific ARB to different contexts or to different ARBs should be avoided. The simple conclusion bullets outlined below may help in driving our clinical choices.

(a) Valsartan on top of optimized pharmacological therapy reduced the risk of cardiovascular events and, in particular, the risk of stroke in patients with high cardiovascular risk. In patients with heart failure and LV dysfunction, valsartan on top of optimized therapy including an ACE-inhibitor, significantly reduced morbidity/mortality combined endpoint and significantly reduced the rate of re-hospitalization due to worsening of heart failure, thereby improving quality of life in these patients and reducing health care costs. In patients with myocardial infarction complicated by heart failure or LV dysfunction, alone or combined, valsartan was the sole ARB which reduced morbidity and mortality, with a protective effect similar to the ACE-inhibitor comparator captopril. Valsartan is therefore the ARB with the largest scientific documentation along the different steps of the cardiovascular disease continuum.

(b) Losartan was superior to the beta-blocker atenolol in reducing the risk of stroke in patients with hypertension and LV hypertrophy. In patients with type 2 diabetes and nephropathy, losartan in addition to conventional therapy reduced proteinuria and the progression to end stage renal disease. In patients with chronic heart failure, losartan proved to be an alternative therapeutic option in patients intolerant to ACE-inhibitors.

(c) Candesartan on top of optimized pharmacological therapy reduced morbidity and mortality, as well as the rehospitalization rate, in patients with heart failure and LV dysfunction.

(d) Irbesartan reduced proteinuria and progression to end stage renal disease in patients with type 2 diabetes and nephropathy.

(e) Telmisartan reduced cardiovascular events in a broad population of patients with high cardiovascular risk, with a protective effect similar to the ACE-inhibitor comparator ramipril.

(f) Other ARBs, although effective in reducing BP levels, are not supported by event-based studies dealing with cardiac or renal end organ protection.

\section{Disclosures}

The authors report no conflicts of interest in this work.

\section{References}

1. Dzau VJ, Antman EM, Black HR, et al. The cardiovascular disease continuum validated: clinical evidence of improved patient outcomes: part II: Clinical trial evidence (acute coronary syndromes through renal disease) and future directions. Circulation. 2006;114(25):2871-2891.

2. Dzau VJ, Antman EM, Black HR, et al. The cardiovascular disease continuum validated: clinical evidence of improved patient outcomes: part I: Pathophysiology and clinical trial evidence (risk factors through stable coronary artery disease). Circulation. 2006;114(25):2850-2870.

3. Ho KK, Pinsky JL, Kannel WB, Levy D. The epidemiology of heart failure: the Framingham Study. J Am Coll Cardiol. 1993; 22(4 Suppl A):6A-13A.

4. Staessen JA, Wang JG, Thijs L. Cardiovascular protection and blood pressure reduction: a meta-analysis. Lancet. 2001;358(9290):1305-1315.

5. Schmieder RE. Mechanisms for the clinical benefits of angiotensin II receptor blockers. Am J Hypertens. 2005;18(5 Pt 1):720-730.

6. Carey RM, Siragy HM. Newly recognized components of the renin-angiotensin system: potential roles in cardiovascular and renal regulation. Endocr Rev. 2003;24(3):261-271.

7. Nickenig G, Harrison DG. The AT(1)-type angiotensin receptor in oxidative stress and atherogenesis: part I: oxidative stress and atherogenesis. Circulation. 2002;105(3):393-396.

8. Nickenig G, Harrison DG. The AT(1)-type angiotensin receptor in oxidative stress and atherogenesis: Part II: AT(1) receptor regulation. Circulation. 2002;105(4):530-536.

9. Unger T, Stoppelhaar M. Rationale for double renin-angiotensinaldosterone system blockade. Am J Cardiol. 2007;100(3A):25J-31J.

10. Biollaz J, Brunner HR, Gavras I, Waeber B, Gavras H. Antihypertensive therapy with MK 421: angiotensin II - renin relationships to evaluate efficacy of converting enzyme blockade. J Cardiovasc Pharmacol. 1982;4(6):966-972.

11. Struthers AD. Aldosterone escape during ACE inhibitor therapy in chronic heart failure. Eur Heart J. 1995;16(Suppl N):103-106.

12. Siragy HM. Angiotensin receptor blockers: how important is selectivity? Am J Hypertens. 2002;15(11):1006-1014.

13. Lewington S, Clarke R, Qizilbash N, Peto R, Collins R. Age-specific relevance of usual blood pressure to vascular mortality: a meta-analysis of individual data for one million adults in 61 prospective studies. Lancet. 2002;360(9349):1903-1913.

14. Turnbull F. Effects of different blood-pressure-lowering regimens on major cardiovascular events: results of prospectively-designed overviews of randomised trials. Lancet. 2003;362(9395):1527-1535.

15. Mancia G, De Backer G, Dominiczak A, et al. Guidelines for the Management of Arterial Hypertension: The Task Force for the Management of Arterial Hypertension of the European Society of Hypertension (ESH) and of the European Society of Cardiology (ESC). J Hypertens. 2007;25(6):1105-1187.

16. Lithell H, Hansson L, Skoog I, et al. The Study on Cognition and Prognosis in the Elderly (SCOPE): principal results of a randomized double-blind intervention trial. J Hypertens. 2003;21(5):875-886.

17. Dahlof B, Devereux RB, Kjeldsen SE, et al. Cardiovascular morbidity and mortality in the Losartan Intervention For Endpoint reduction in hypertension study (LIFE): a randomised trial against atenolol. Lancet. 2002;359(9311):995-1003. 
18. Julius S, Kjeldsen SE, Weber M, et al. Outcomes in hypertensive patients at high cardiovascular risk treated with regimens based on valsartan or amlodipine: the VALUE randomised trial. Lancet. 2004;363(9426):2022-2031.

19. Mochizuki S, Dahlof B, Shimizu M, et al. Valsartan in a Japanese population with hypertension and other cardiovascular disease (Jikei Heart Study): a randomised, open-label, blinded endpoint morbiditymortality study. Lancet. 2007;369(9571):1431-1439.

20. Yusuf S, Teo KK, Pogue J, et al. Telmisartan, ramipril, or both in patients at high risk for vascular events. $N$ Engl J Med. 2008;358(15): 1547-1459.

21. Kassler-Taub K, Littlejohn T, Elliott W, Ruddy T, Adler E; Comparative efficacy of two angiotensin II receptor antagonists, irbesartan and losartan in mild-to-moderate hypertension. Irbesartan/Losartan Study Investigators. Am J Hypertens. 1998;11(4 Pt 1):445-453.

22. Mallion J, Siche J, Lacourciere Y. ABPM comparison of the antihypertensive profiles of the selective angiotensin II receptor antagonists telmisartan and losartan in patients with mild-to-moderate hypertension. J Hum Hypertens. 1999;13(10):657-664.

23. Andersson $\mathrm{OK}, \mathrm{Neldam} \mathrm{S}$. The antihypertensive effect and tolerability of candesartan cilexetil, a new generation angiotensin II antagonist, in comparison with losartan. Blood Press. 1998;7(1):53-59.

24. Hedner T, Oparil S, Rasmussen K, et al. A comparison of the angiotensin II antagonists valsartan and losartan in the treatment of essential hypertension. Am J Hypertens. 1999;12(4 Pt 1):414-417.

25. Flather MD, Yusuf S, Kober L, et al; Long-term ACE-inhibitor therapy in patients with heart failure or left-ventricular dysfunction: a systematic overview of data from individual patients. ACE-Inhibitor Myocardial Infarction Collaborative Group. Lancet. 2000;355(9215):1575-1581.

26. Dickstein K, Kjekshus J. Effects of losartan and captopril on mortality and morbidity in high-risk patients after acute myocardial infarction: the OPTIMAAL randomised trial. Optimal Trial in Myocardial Infarction with Angiotensin II Antagonist Losartan. Lancet. 2002;360(9335): 752-760.

27. Pfeffer MA, McMurray JJ, Velazquez EJ, et al. Valsartan, captopril, or both in myocardial infarction complicated by heart failure, left ventricular dysfunction, or both. N Engl J Med. 2003;349(20):1893-1906.

28. Pitt B, Segal R, Martinez FA, et al. Randomised trial of losartan versus captopril in patients over 65 with heart failure (Evaluation of Losartan in the Elderly Study, ELITE). Lancet. 1997;349(9054):747-752.
29. Pitt B, Poole-Wilson PA, Segal R, et al. Effect of losartan compared with captopril on mortality in patients with symptomatic heart failure: randomised trial - the Losartan Heart Failure Survival Study ELITE II. Lancet. 2000;355(9215):1582-1587.

30. Cohn JN, Tognoni G. A randomized trial of the angiotensin-receptor blocker valsartan in chronic heart failure. $N$ Engl J Med. 2001; 345(23):1667-1675.

31. McMurray JJ, Ostergren J, Swedberg K, et al. Effects of candesartan in patients with chronic heart failure and reduced left-ventricular systolic function taking angiotensin-converting-enzyme inhibitors: the CHARM-Added trial. Lancet. 2003;362(9386):767-771.

32. Granger CB, McMurray JJ, Yusuf S, et al. Effects of candesartan in patients with chronic heart failure and reduced left-ventricular systolic function intolerant to angiotensin-converting-enzyme inhibitors: the CHARM-Alternative trial. Lancet. 2003;362(9386):772-776.

33. Yusuf S, Pfeffer MA, Swedberg K, et al. Effects of candesartan in patients with chronic heart failure and preserved left-ventricular ejection fraction: the CHARM-Preserved Trial. Lancet. 2003;362(9386): 777-781.

34. Massie BM, Carson PE, McMurray JJ, et al. Irbesartan in patients with heart failure and preserved ejection fraction. $N \mathrm{Engl} \mathrm{J} \mathrm{Med.}$ 2008;359(23):2456-2467

35. Lewis EJ, Hunsicker LG, Bain RP, Rohde RD. The effect of angiotensinconverting-enzyme inhibition on diabetic nephropathy. The Collaborative Study Group. N Engl J Med. 1993;329(20):1456-1462.

36. Ravid M, Savin H, Jutrin I, Bental T, Katz B, Lishner M. Long-term stabilizing effect of angiotensin-converting enzyme inhibition on plasma creatinine and on proteinuria in normotensive type II diabetic patients. Ann Intern Med. 1993;118(8):577-581.

37. Parving HH, Lehnert H, Brochner-Mortensen J, Gomis R, Andersen S, Arner P. The effect of irbesartan on the development of diabetic nephropathy in patients with type 2 diabetes. $N$ Engl J Med. 2001;345(12): 870-878.

38. Brenner BM, Cooper ME, de Zeeuw D, et al. Effects of losartan on renal and cardiovascular outcomes in patients with type 2 diabetes and nephropathy. N Engl J Med. 2001;345(12):861-869.

39. Lewis EJ, Hunsicker LG, Clarke WR, et al. Renoprotective effect of the angiotensin-receptor antagonist irbesartan in patients with nephropathy due to type 2 diabetes. N Engl J Med. 2001;345(12):851-860.
Vascular Health and Risk Management

\section{Publish your work in this journal}

Vascular Health and Risk Management is an international, peerreviewed journal of therapeutics and risk management, focusing on concise rapid reporting of clinical studies on the processes involved in the maintenance of vascular health; the monitoring, prevention and treatment of vascular disease and its sequelae; and the involvement of

\section{Dovepress}

metabolic disorders, particularly diabetes. This journal is indexed on PubMed Central and MedLine. The manuscript management system is completely online and includes a very quick and fair peer-review system, which is all easy to use. Visit http://www.dovepress.com/ testimonials.php to read real quotes from published authors. 